Abstracta Iranica Abstracta Iranica

Revue bibliographique pour le domaine irano-aryen

Volume 30 | 2010

Comptes rendus des publications de 2007

L'archéologie du Fārs à l'époque hellénistique. Quatre leçons au Collège de France, 8, 15, 22 et 29 mars 2007. Paris, de Boccard, 2007, 179 p., 100 fig. (Persika, 11)

Rémy Boucharlat

(2) OpenEdition

1 Journals

Édition électronique

URL : http://journals.openedition.org/abstractairanica/37706

DOI : $10.4000 /$ abstractairanica.37706

ISSN : 1961-960X

Éditeur :

CNRS (UMR 7528 Mondes iraniens et indiens), Éditions de l'IFRI

Édition imprimée

Date de publication : 8 avril 2010

ISSN : 0240-8910

Référence électronique

Rémy Boucharlat, «L'archéologie du Fārs à l'époque hellénistique. Quatre leçons au Collège de France, 8,

15, 22 et 29 mars 2007. Paris, de Boccard, 2007, 179 p., 100 fig. (Persika, 11) », Abstracta Iranica [En

ligne], Volume 30 | 2010, document 104, mis en ligne le 08 avril 2010, consulté le 26 septembre 2020

URL : http://journals.openedition.org/abstractairanica/37706 ; DOI : https://doi.org/10.4000/

abstractairanica.37706

Ce document a été généré automatiquement le 26 septembre 2020.

Tous droits réservés 


\title{
L'archéologie du Fārs à l'époque hellénistique. Quatre leçons au Collège de France, 8, 15, 22 et 29 mars 2007. Paris, de Boccard, 2007, 179 p., 100 fig. (Persika, 11)
}

\author{
Rémy Boucharlat
}

1 L'époque hellénistique est ici la période de la domination séleucide et le début de l'époque parthe jusqu'au $\mathrm{II}^{\mathrm{e}} \mathrm{s}$. av. J.-C., avec des incursions au-delà, du fait de la nouvelle datation proposée pour certains documents. Est traitée l'ancienne Perse, à laquelle correspondent les provinces modernes du Fars et de Bushehr. L'A., archéologue d'abord, mais compétent dans l'étude critique des textes classiques occidentaux reprend la question traitée naguère sur un plan plus historique par J. Wiesehöfer Die 'dunklen Jahrhunderte' der Persis, 1994 (Zetemata 90), München. Progrès des études et nouvelles découvertes justifiaient le renouvellement de l'entreprise.

Le livre offre quatre « leçons » (études) distinctes dans lesquelles la documentation est parfois la même, mais abordée sous un angle différent: I « Habitats anciens et fondations hellénistiques du plateau iranien : les témoignages littéraires, épigraphiques et archéologiques concernant la région du Fārs ». II «Bâtiments et cultes de l'Iran à l'époque hellénistique». III "L'apport hellénistique à la production artistique et artisanale du Fārs, des Achéménides aux Sassanides». IV «Le Fārs sous le règne des souverains locaux : les témoignages archéologiques et épigraphiques ».

Le chapitre I, dépassant le Fars, aborde la question des fondations d'Alexandre et de ses successeurs et propose également une nouvelle lecture de la carte de Ptolémée concernant le centre et sud de l'Iran (pp. 28-33) entre autres, Antioche de Perside, que l'on situe souvent sur la côte du golfe Persique, mais à localiser plus probablement à quelques dizaines de kilomètres de la côte, près la ville moderne de Borazjan, où les vestiges achéménides sont aujourd'hui nombreux. 
4 Le chapitre II, s'attache longuement à l'énigmatique «temple des Frataraka ", à $200 \mathrm{~m}$ au nord de la terrasse de Persépolis, fouille non publiée de E. Herzfeld. Il a livré cinq plaques de calcaire portant chacune le nom d'une divinité grecque en grec (fin IV ou début $\mathrm{III}^{\mathrm{e}} \mathrm{s}$. av. J.-C.) et un ensemble de constructions que l'on a maintenant divisé en deux bâtiments distincts non contemporains dans l'état qui nous est parvenu. L'une contient dans la salle principale un socle qui serait, non pas celui d'un autel, mais d'une statue grecque. D'autres lieux de culte d'Iran sont à peine reconnus ou localisés comme celui qui ferait écho aux inscriptions grecques de Nehavand et Kermanshah.

Dans le chapitre III, l'apport hellénistique à la production artistique du Fars, PC se livre à une analyse soigneuse de plusieurs documents artistiques de l'époque hellénistique telle qu'il l'a définie. Certains restent datés de la période séleucide, mais d'autres sont rajeunis par l'A. jusqu'à la période impériale romaine.

6 Le dernier chapitre est consacré à ce qui est souvent qualifié de début de la renaissance iranienne, bien avant les Sassanides, la période qui voit le retour de l'aristocratie locale, dans le Fars avec la dynastie des Frataraka, non pas au début du III ${ }^{\mathrm{e}}$ s. av. J.-C., mais un siècle plus tard. PC soutient que ce changement politique ne signifie pas l'indépendance du Fars à ce moment, ni plus tard sous les Parthes, contrairement aux idées reçues.

7 Ces quatre études sont des réflexions nouvelle, en même temps qu'elles apportent des informations très actuelles, souvent de première main, car $\mathrm{PC}$ travaille dans la région depuis plusieurs années. Elles pourront surprendre ceux qui voient dans la conquête gréco-macédonienne de l'Iran une rupture sans retour. A côté de l'adoption d'éléments inconnus sous les Achéménides dans le Fars comme la monnaie, la langue et l'écriture grecques, les interprétations de l'iconographie grecque ne participent pas toujours d'un réel syncrétisme religieux, et n'entravent pas le maintien puis le retour des traditions locales achéménides bien avant l'époque sassanide qui saura les exalter, sans pour autant se priver d'introduire de nouveaux éléments occidentaux, de l'Orient romain cette fois.

\section{INDEX}

Thèmes : 3.2.3. Séleucides, Parthes et Sassanides

\section{AUTEURS}

RÉMY BOUCHARLAT

CNRS - Lyon 